\title{
Up in the air: threats to Afromontane biodiversity from climate change and habitat loss revealed by modelling and landscape genetics of the Ethiopian Highlands long-eared bat
}

\author{
Orly Razgour ${ }^{1}$, Mohammed Kasso $^{2}$, Helena Santos ${ }^{3}$, and Javier Juste ${ }^{4}$ \\ ${ }^{1}$ University of Exeter \\ ${ }^{2}$ Dire Dawa University \\ ${ }^{3}$ Research Network in Biodiversity and Evolutionary Biology, Research Centre in \\ Biodiversity and Genetic Resources (InBIO-CIBIO) \\ ${ }^{4}$ Estacion Biologica de Donana CSIC
}

June 2, 2020

\begin{abstract}
Whilst climate change is recognised as a major future threat to biodiversity, most species are currently threatened by extensive human-induced habitat loss, fragmentation and degradation. Tropical high altitude alpine and montane forest ecosystems and their biodiversity are particularly sensitive to temperature increases under climate change, but they are also subject to accelerated pressures from land conversion and degradation due to a growing human population. We studied the combined effects of anthropogenic land-use change, past and future climate changes and mountain range isolation on the endemic Ethiopian Highlands long-eared bat, Plecotus balensis, an understudied bat that is restricted to the remnant natural high altitude Afroalpine and Afromontane habitats. We integrated ecological niche modelling, landscape genetics and model-based inference to assess the genetic, geographic and demographic impacts of past and recent environmental changes. We show that mountain range isolation and historic climates shaped population structure and patterns of genetic variation, but recent anthropogenic land-use change and habitat degradation are associated with a severe population decline and loss of genetic diversity. Our models predict that the suitable niche of this bat has been progressively shrinking since the last glaciation period. This study highlights threats to tropical montane biodiversity, squeezed to higher altitudes under climate change while losing genetic diversity and suffering population declines due to anthropogenic land-use change. We conclude that assessments of threats to biodiversity under global change should adopt a holistic approach, simultaneously studying the effects of multiple threats across temporal scales based on genetic, ecological and geographic information.
\end{abstract}

\section{Introduction}

Clusters of alpine high mountain ecosystems that are isolated by different environmental conditions in the intervening lowlands can behave as authentic archipelagos. These sky islands contain unique diversity and provide natural laboratories to study evolution, speciation and the effects of habitat fragmentation (Hedberg, 1969; McCormack, Huang, \& Knowles, 2009). However, their extent of isolation has changed with climatic fluctuations during the Quaternary, in particular in tropical regions. Colder conditions during glacial periods led to the expansion of high altitude alpine and montane forest ecosystems into lower elevations, thus facilitating population expansion and connectivity between populations previously isolated on mountain tops (Hewitt, 2000). These cycles and fluctuations in gene flow promoted differentiation processes that led to exceptionally high levels of endemism (Williams, Vivero, Spawls, Anteneh, \& Ensermu, 2004). On the 
other hand, these ecosystems are especially sensitive to future climate change, and as a result of climatic warming their area is rapidly diminishing (Moritz \& Agudo, 2013), a process which will increase the isolation and extinction risk of their associated flora and fauna. This process is expected to be particularly intense in the scarce alpine environments distributed at high elevations across the tropics. Tropical mountains are predicted to experience the highest levels of extinctions and changes to fauna assemblages under future climate change (Lawler et al., 2009). High altitude species living close to mountain tops may lose their entire range as their suitable climatic regime and its associated ecosystem disappears with increasing temperatures (Pimm, 2009; Williams, Jackson, \& Kutzbach, 2007).

This problem is especially acute in under-studied and highly threatened areas like the Ethiopian Highlands, where accelerated land conversion and degradation is placing further pressures on biodiversity (Yalden, Largen, Kock, \& Hillman, 1996). The Ethiopian Highlands are a vast extent of high ground rising up to 4620 masl with a low altitude limit of 1500 masl. They cover an area of 519,278 $\mathrm{km}^{2}$ in the otherwise arid zone of the Horn of Africa and include $73 \%$ of the Afroalpine biome (areas above 3200 masl) in Sub-Saharan Africa (Williams et al., 2004). The Great Rift Valley crosses the Ethiopian central highlands dividing them into two main blocks, north-east and south-west (Ebinger et al., 2000).

The Afroalpine biome shows one of the highest rate of endemism in the world due to a combination of their relative small areas, high isolation and climatic history (Reyes-Velasco, Manthey, Freilich, \& Boissinot, 2018; S. D. Williams et al., 2004). These endemics are either of Palearctic (e.g. the Ethiopian ibex, Capra walie, the Ethiopian long-eared bat, Plecotus balensis ) or Afrotropical origin (e.g. geladas monkeys, Theropithecus gelada, the mountain nyala, Tragelaphus buxtoni ) (Harmsen, Spence, \& Mahaney, 1991). Although the source of colonisers of this truly unique environment is probably more complex, including also long-distance vagrants like the endemic plover (Vanellus melanocephala) (Kingdon, 1990). Rapid human population growth in Ethiopia over the past 150 years, from approximately 6.6 million in 1868 (Nyssen et al., 2014) to more than 100 million (UN, 2019), and the corresponding increase in pressure on natural environments and human encroachment into national parks and other protected areas has resulted in extensive habitat degradation (Kidane, Stahlmann, \& Beierkuhnlein, 2012). This pressure has been implicated with biodiversity losses, from the decline of endemic frogs (Gower et al., 2013) to the decline of large flagship mammal species such as the endemic Ethiopian wolf, Canis simensis (Stephens, d'Sa, Sillero-Zubiri, \& Leader-Williams, 2001). However, some signs of vegetation recovery have been observed since the early $21^{\text {st }}$ century following the initiation of environmental recovery programs in the 1980s and the establishment of new protected areas closing up to $15 \%$ of the country to livestock grazing (Nyssen et al., 2014).

Recently, a new species of the long-eared bat genus Plecotus was described in the Ethiopian Highlands above $3000 \mathrm{~m}$, the Bale long-eared bat, Plecotus balensis, which is endemic to Ethiopia and possibly Eritrea (Juste et al., 2004; Kruskop \& Laverenchenko, 2000), and is known by only a few specimens from just seven localities (Benda, Kiefer, Hanák, \& Veith, 2004). The genus Plecotus is widely distributed across the Palearctic, and is characterised by high cryptic diversification and specific altitudinal and climatic associations (Spitzenberger, Strelkov, Winkler, \& Haring, 2006). Due to their limited long-distance dispersal abilities and habitat specialisations, Plecotus bats are particularly sensitive to habitat loss (Razgour et al., 2014) and the effects of future climate change (Razgour et al., 2013). Bats can be good bio-indicators of environmental change (Jones, Jacobs, Kunz, Willig, \& Racey, 2009) and have been used to test biogeographical hypotheses on the role of topographic barriers and past climate change in delimiting species distribution and shaping genetic composition (e.g. Flanders et al., 2009; Razgour et al., 2013).

We use this recently described high altitude bat to study how sky islands and historic versus current patterns of environmental heterogeneity shape the distribution and genetic diversity of their unique fauna. We project ecological niche models (ENMs) across temporal scales to track the effect of past climate changes on range suitability for $P$. balensis and predict impacts of future changes. We integrate approximate Bayesian computation inference of demographic history with landscape genetics analysis and markers with different mutation rates to disentangle the impact of historic vicariance events versus recent anthropogenic habitat loss and degradation on population size, genetic diversity and genetic connectivity of sky island biodiversity. 
Our study highlights threats to tropical montane biodiversity due to the combined effects of multiple stressors, being squeezed into higher altitudes due to climate change while losing genetic diversity and suffering population declines due to anthropogenic land-use change.

\section{Materials and Methods}

Bats were sampled during 2014 and 2015 in five isolated mountain ranges across the Ethiopian Highlands: 1) Bale Mountains National Park, the largest and southernmost massif that covers partially the most extensive Afroalpine area in the continent (Hillman, 1986), 2) Arsi Mountains National Park of Chillalo-Galama Mountains, 3) Guassa Community Conservation Area, 4) Mount Abune Yosef, and 5) the Simien Mountains National Park (Fig. 1). The Ethiopian Highlands include unique ecosystems typically characterised by Afromontane forests up to 3200 masl, Afroalpine wet and dry grasslands above $3500 \mathrm{~m}$ and Afroalpine moorland habitat above $4000 \mathrm{~m}$. The Afromontane forest habitat includes the endemic Ethiopian juniper (Juniperus procera) and African redwood (Hagenia abyssinica) in the drier northern slopes and Erica (Erica arborea ) and yellow wood (Podocarpus sp.) forests in the warmer and more humid southern slopes. We obtained $3 \mathrm{~mm}$ wing biopsies from 50 Plecotus balensis bats from 19 sites (Supplementary Table S1). Bats were caught in two distinct ecoregions: Afromontane woodland (2795-3492 m; 30 bats) and Afroalpine grasslands and moorlands (3773-4224 m; 20 bats). In Bale, a sufficient number of bats was caught in each ecoregion type to separate the mountain range into two populations, 'Bale-D' (Dinsho) for Afromontane woodland and 'Bale-S' (Sanetti Plateau) for Afroalpine moorlands. Because only three individuals were caught in Chillalo-Galama Mountains, samples from this mountain range could only be included in individual-based analyses (ecological niche models, phylogenetic tree, haplotype network and population structure), as well as the demographic history analysis as part of the southern population. Three additional samples collected from two sites around the Abune Yosef Mountain in a former expedition in 1996 were also included in individual-based analyses only.

\section{Ecological niche modelling}

Ecological niche models (ENMs) were generated with the programme MaxEnt v3.4.1 (Phillips, Anderson, \& Schapire, 2006) to determine the potential geographic distribution and ecological requirements of $P$. balensis across the Horn of Africa. The Horn of Africa was selected as the study area because it represents a biotic region that was likely accessible for the species over the relevant time periods covered by the modelling. As only 14 unclustered location records are available for this under-studied species, we used a bias layer to account for potential uneven sampling efforts and low sample sizes. We assigned a value of 10 for mountain ranges surveyed during our expeditions and a value of 1 to the remaining study area. These values were used by Maxent to give weights to random background data during the modelling process so that pseudo-absences better reflect potential geographic bias in sampling efforts (Fourcade, Engler, Rödder, \& Secondi, 2014). Model resolution was set at $\sim 1 \mathrm{~km}(30 \mathrm{arc} \mathrm{sec})$. We generated two types of models. The full model included a combination of climatic [downloaded from WorldClim (www.worldclim.org/)], topographic [including altitude, slope and ruggedness, calculated from SRTM map (https://www2.jpl.nasa.gov/srtm/)], land cover [GlobCover2009 map, European Space Agency (http://due.esrin.esa.int/page_globcover.php) reclassified into 10 general categories], vegetation cover [Normalized Difference Vegetation Index (NDVI) for the dry and wet seasons, MOD13A3 (https://lpdaac.usgs.gov/)], ecoregions (WWF ecoregions map; Olson et al., 2001), and human footprint variables [Global human footprint v2 2005, NASA (http://sedac.ciesin.columbia.edu/data/set/wildareasv2-human-footprint-geographic)]. The climatic model included only climatic and static topographic variables that could be projected to the future (ruggedness and slope). We removed highly correlated variables $[\mathrm{R}>|0.75|$; tested with ENMTools v1.3 (Warren, Glor, \& Turelli, 2010)] and variables that did not contribute to model gain (Supplementary Table S2 for final model variables). Final models included a regularization value of 2 and three features (linear, quadratic and product), selected based on AICc scores obtained with ENMTools, and 1500 iterations. Model testing was carried out with 100 bootstrap replications using $20 \%$ 
of data for model testing. Output maps were converted to binary maps based on the thresholding method that maximises sensitivity and specificity (Liu, White, \& Newell, 2013). Areas with values that fell above the threshold were considered as suitable for the bat.

Models were hind-casted to the Last Glacial Maximum (LGM) and mid-Holocene, and projected to the future (2070) using three General Circulation Models (CCSM4, MIROC-ESM, MPI-ESM-LR) for each time period, and two Representative Concentration Pathways (RCP) scenarios for future projections only, the 'worst case' scenario, RCP $+8.5 \mathrm{~W} / \mathrm{m}^{2}$, and the more moderate $\mathrm{RCP}+4.5 \mathrm{~W} / \mathrm{m}^{2}$ scenario (IPCC, 2013). In our projected models we included the only climatic variable that affected the distribution of $P$. balensis , maximum temperature (BIO5, WorldClim) and a static topographic variable, topographic ruggedness (calculated from SRTM map).

\section{Generating the genetic datasets}

Genomic DNA was extracted from all wing biopsy samples. The extraction protocol consisted of DNA precipitation with isopropanol after purification using saline precipitation. We selected three markers with different mutation rates, covering events that occurred during the Pleistocene (mitochondrial DNA fragments) versus recent-contemporary impacts from the last few decades-centuries (microsatellites). Two mitochondrial DNA (mtDNA) fragments were amplified: a 650 bp fragment of the gene cytochrome b (cytb) using the primers MOLCIT-F (Ibáñez, García-Mudarra, Ruedi, Stadelmann, \& Juste, 2006) and MVZ16 (Smith \& Patton, 1993); and a 460 bp fragment of the hyper-variable region (HV1) of the control region using the primers L15926 and CSBF-R (Wilkinson \& Chapman, 1991). The PCR reaction (20 $\mu$ l final reaction volume) included $0.5-5 \mu \mathrm{l}$ of DNA extract, $0.5 \mu \mathrm{M}$ of each primer, $2 \mathrm{nM}$ of $\mathrm{MgCl}_{2}, 0.2 \mathrm{nM}$ of dNTPs, $0.2 \mathrm{mg}$ BSA, and 0.5 units of Taq-Polimerase. Thermo-cycling consisted of $4 \mathrm{~min}$ initial denaturation at $94^{\circ} \mathrm{C}$ followed by 35 cycles of $60 \mathrm{~s}$ at $94^{\circ} \mathrm{C}, 30 \mathrm{~s}$ at $52^{\circ} \mathrm{C}$ (for both pairs) and $90 \mathrm{~s}$ at $72^{\circ} \mathrm{C}$ and a final extension of $10 \mathrm{~min}$ at $72^{\circ} \mathrm{C}$. The PCR products were sequenced using ABI 3100 automated sequencers (PE Biosystems, Warrington, UK) and DNA fragments were aligned and edited using Geneious v. R11 software (Biomatters Ltd).

Samples were also genotyped for 19 polymorphic autosomal microsatellite loci previously developed for the genus (Razgour et al., 2013). The forward primer of each locus pair was labelled fluorescently with HEX or 6-FAM (Applied Biosystems), and microsatellites were combined into six multiplex sets. Each 10ul PCR plex contained 2-4 primer sets (each set at a concentration of $0.2 \mu \mathrm{M}$ and a total volume of $1 \mu \mathrm{l}$ ), $5 \mu \mathrm{l}$ Qiagen multiplex PCR master mix

and $2 \mu$ l DNA. We used the following PCR program: initial denaturation at $95^{\circ} \mathrm{C}$ for $15 \mathrm{~min}$, followed by 35 cycles of $94^{\circ} \mathrm{C}$ for $30 \mathrm{~s}, 57^{\circ} \mathrm{C}$ for $90 \mathrm{~s}$ and $72^{\circ} \mathrm{C}$ for $60 \mathrm{~s}$, followed by a final extension at $60^{\circ} \mathrm{C}$ for $30 \mathrm{~min}$. PCR products were sent for fragment analysis in Dnaseq (University of Dundee, UK). Allele sizes were assigned using GeneMapper (Applied Biosystems, USA). All loci retained in the analysis did not depart from HardyWeinberg equilibrium expectations, were not in linkage disequilibrium and had a low frequency of null alleles in most populations [tested with GENEPOP v4.2 (Rousset, 2008) and CERVUS v3.0.3 (Kalinowski, Taper, \& Marshall, 2007)].

\section{Power analysis}

We tested the power of our genetic dataset to detect population structure (assignment tests and connectivity) and identify a population bottleneck using the Sample Planning Optimization Tool for conservation and population Genetics (SPOTG; Hoban, Gaggiotti, \& Bertorelle, 2013). Assignment tests had very high power (0.98) with 20 individuals and two populations and high power with 10 individuals and five populations (0.86). Similarly, connectivity analysis had high power (0.87) even with our minimum population size $(7$ individuals), while for 10 individuals, power has increased to very high (0.97). The power to detect a recent bottleneck varied depending on the extent of the bottleneck and sample size. For a severe bottleneck, a sample size of 20 individuals had high power (79\%), while 10 individuals had insufficient power (27\%). For a 
moderate bottleneck, an analysis with 20 individuals had just below minimal chance of success (46\%), and 10 individuals had very low power (20\%).

\section{Genetic data analysis}

Mitochondrial DNA sequences from the cytb and HVI regions were aligned and concatenated into a single sequence (1110 bp) with BioEdit v7.2.0 (Hall, 1999) and collapsed into haplotypes with DAMBE v6 (Xia \& Xie, 2001). Bayesian phylogenetic trees were constructed for the concatenated cytb and HVI sequences in MrBayes v3.2.1 (Ronquist et al., 2012), usingPlecotus austriacus as outgroup to root the tree. We ran $4 \times 10^{7}$ generations with four chains, sampled every 200th generation, and two simultaneous runs, discarding the first $25 \%$ of trees as burn-in. We used the Hasegawa-Kishino-Yano (HKY) model of DNA substitution with proportion of invariable sites model of rate variation for the cytb sequences and the HKY model with gamma-distributed rate variation for the HVI sequences [selected by jModelTest2 v0.1.10 (Darriba, Taboada, Doallo, \& Posada, 2012) based on BIC values]. Trees and posterior probabilities were visualised with Figtree v1.3.1 (http://tree.bio.ed.ac.uk/software/figtree/). Parsimony haplotype network for the concatenated sequences was constructed with NETWORK (v4.610, Fluxus Technology), employing the median-joining network algorithm and the Greedy FHP distance calculation method. We calculated nucleotide polymorphism, haplotype diversity, genetic divergence and differentiation between populations in DnaSP v5.10 (Librado \& Rozas, 2009).

Population genetics summary statistics for the microsatellite dataset were performed in GenAlEx v6.4 (Peakall \& Smouse, 2006) and FSTAT v2.9.3.2 (Goudet, 1995) correcting for differences in sample sizes. Levels of inbreeding within each population were calculated using the TrioML measure in Coancestry (Wang, 2011). Linear models were performed in R (CRAN) to related levels of genetic diversity (allelic richness) and inbreeding to NDVI during the dry season, human footprint index and cover of key land-use types likely to either positively (forest) or negatively (arable land) affect habitat quality for bats. Cover of the land-use types was measured in ArcGIS v10.3.1 (ESRI) within $5 \mathrm{~km}$ buffers around population capture locations using the GlobCover 2009 map. Values of NDVI and human footprint index were averaged across the $5 \mathrm{~km}$ buffers. We used $5 \mathrm{~km}$ buffer around capture sites to reflect the potential home range of the species, estimated based on the home range size of its better studied cryptic congener Plecotus austriacus (Razgour, Hanmer, \& Jones, 2011).

Extent of genetic differentiation between populations was calculated using two measures: $\mathrm{F}_{\mathrm{st}}$ in SPAGeDi (Hardy \& Vekemans, 2002) and Jost's D (Jost, 2008) in GenAlEx v6.4. Individual-based Bayesian assignment tests implemented in STRUCTURE v2.3.3 (Pritchard, Stephens, \& Donnelly, 2000) were used to infer genetic population structure, varying number of clusters (K) from 1 to 10 , with 10 replicates and $10^{6}$ Markov Chain Monte Carlo (MCMC) generations following a burn-in phase of $5 \times 10^{5}$ generations. The number of distinct clusters was determined using STRUCTURE HARVESTER (Earl \& vonHoldt, 2012) based on Evanno's delta K method and mean log-likelihood. Cluster assignment was visualised with DISTRUCT (Rosenberg, 2003).

\section{Landscape Genetics analysis}

We used the landscape genetics approach to determine how landscape heterogeneity affects functional connectivity and gene flow between mountain range populations of $P$. balensis. The analysis included landscape variables that were deemed to impede or facilitate movement in this bat given what is known about its habitat use and geographic distribution, including topographic variables (altitude and ruggedness), ecoregions, forest (percent tree cover), land cover (land cover and NDVI), hydrology (distance to streams), and human impact variables (human footprint index and night lights index). Landscape variables were converted to resistance cost surfaces in ArcGIS and were assigned different resistance costs based on knowledge of the ecology of this species and its better-studied cryptic congeners. Resistance costs ranged from one, no resistance to movement, to 100, strong barrier to movement (see Supplementary Table S3 for list of varia- 
bles, their sources and different allocated resistance costs). Circuitscape v4.0.5 (McRae, 2006) was used to calculate resistance distance matrices between populations based on the cumulative cost of movement due to landscape resistance. We used multiple regression on distance matrices in the $\mathrm{R}$ package ecodist (Goslee \& Urban, 2007) to select the best combination of resistance costs for each landscape variable based on strength of correlation with genetic distance ( $F_{\text {st }}$ and Jost's D) between populations (Supplementary Table S4).

We compared nine candidate sets of hypotheses for the effect of the landscape on genetic connectivity: topographic (altitude), land-use (land cover map), anthropogenic (human footprint index), ecoregions (WWF ecoregions map), forest (percent tree cover), hydro (distance to streams), hydro-land (streams + land cover), anthropo-eco (human index + ecoregions) and anthropo-topo (human index + altitude). We used the Maximum Likelihood Population Effect (MLPE) approach (Van Strien, Keller, \& Holderegger, 2012) and the R packages lme4 (Bates, Mächler, Bolker, \& Walker, 2015) and usdm (Naimi, Hamm, Groen, Skidmore, \& Toxopeus, 2014). To reduce model collinearity we only included variables with VIF $<4$ in each hypothesis tested. We compared evidence for models being closest to the truth based on AICc and BIC evidence weights (Van Strien et al., 2012). To account for the effect of geographic distance on genetic connectivity, we divided the $\log$ measure of genetic distance ( $\mathrm{F}_{\text {st }}$ or Jost's D) by log Euclidean distance between populations. All variables were log transformed to comply with model assumptions of normal distribution.

\section{Approximate Bayesian computation (ABC) inference of evolutionary history}

The demographic history of $P$. balensis was reconstructed using the ABC approach implemented in DIYABC v2.1.0 (Cornuet et al., 2014) in order to identify whether recent changes in population size have occurred in response to anthropogenic land-use change and habitat fragmentation and degradation. Small sample sizes meant we could not compare the evolutionary history of each mountain range, but only the wider geographical areas. Therefore, we divided the dataset into samples from the north-west $(n=28)$ versus south-east $(n=22)$ of the Rift Valley due to its role in population structure (see Results section). We tested four competing scenarios of population changes: 1) a large ancient population split into two smaller populations, no change in population sizes; 2) population expansion after split; 3) after population split, both populations declined recently; and 4) after population split recent decline in the south-eastern population only (Supplementary Fig. S1 for scenarios). Population split dates were kept flexible, ranging from pre-post LGM (200-200,000 years ago), while recent decline dates were set at 20-1000 years ago.

$\mathrm{ABC}$ analysis was carried out on the combined mtDNA and microsatellite datasets, including only recent samples (from 2014-2015). MtDNA substitution model and parameters were defined based on jModelTest2 results. We simulated $10^{6}$ datasets per scenario tested, and included most available summary statistics (18 in total). The posterior probability of scenarios was estimated using a weighted polychotomous logistic regression. We empirically evaluated the power of the model to discriminate among scenarios (confidence in scenario choice) by simulating pseudo-observed datasets with the different scenarios and calculating false allocation rates. We evaluated model specificity (type 1 error) by simulating 500 pseudo-observed datasets with the scenario selected by the ABC analysis and calculating rates of false scenario assignment. Model sensitivity (type 2 error) was calculated based on the proportion of 500 pseudo-observed datasets simulated with other scenarios that were assigned to the scenario selected by the ABC analysis. We carried out model checking for the most probable scenario through performing a PCA on 1000 simulated datasets generated from posterior parameter distributions and the observed dataset. We evaluated bias and precision on parameter estimation by calculated the relative mean bias and Relative Median Absolute Deviation (RMedAD) based on comparing 500 pseudo-observed simulated datasets to 10,000 simulated datasets closest to observed dataset of each parameter (Cornuet, Ravigné, \& Estoup, 2010; Cornuet et al., 2014). 


\section{Results}

Of the 50 bats captured during this study, 39 were males, five of which were sub-adults, and only 11 were females, four of which were reproductive (lactating). All females and sub-adults were caught exclusively in Juniperus procera or Erica arborea forests. Only adult males were caught at the higher altitude Afroalpine moorlands (Supplementary Table S1).

\section{Ecological niche models}

Models had very high discrimination ability (AUCtrain $=0.997$; AUCtest $=0.995 \pm 0.01$ ). The main variables affecting the probability of occurrence of $P$. balensis were maximum temperatures (highest contribution to model and highest effect on gain when removed), Ethiopian Afroalpine moorland and Ethiopian montane grassland and woodland ecoregions, high topographic ruggedness and forest land cover (Supplementary Table S2). All other variables, including anthropogenic impact (human footprint), contributed very little to the model $(<0.5 \%)$, and were therefore removed. The model projected suitable areas for $P$. balensis (i.e. falling above the threshold that maximises model sensitivity and specificity) across the Ethiopian Highlands, split into mountain ranges to the north and south of the Rift Valley, as well as mountain ranges in Eritrea and Somaliland (Fig. 2; Supplementary Fig. S2). However, only less than $1 \%$ of the Horn of Africa was predicted to be suitable for $P$. balensis . Climatic models projected across temporal scales predicted that the climatically suitable range was 4.5 times larger during the LGM and 3.8 times larger during the mid-Holocene. Only a quarter of the current range was projected to remain suitable by the end of the century, equating to $5.6 \%$ of the LGM suitable range (based on the more severe RCP 8.5 scenario; Fig. 2; Supplementary Fig. S2; Table 1).

\section{Genetic composition}

We identified 32 unique cytb haplotypes and 34 unique HVI haplotypes (Genbank Accession numbers to be added after acceptance). Each mountain range had unique haplotypes and no haplotypes were shared between mountain ranges. Overall, the Bayesian phylogenetic tree and haplotype network showed a strong effect of mountain ranges on genetic population structure and supported a split between haplotypes to the north-west and south-east of the Rift Valley. The main divergence was identified between haplotypes from Bale [Harenna Forest and Sanetti Plateau (Bale-S)] and the remaining haplotypes, followed by the divergence of Simien haplotypes (Fig. 3b). Population structure analysis of the microsatellite dataset split individuals into two clusters $(\mathrm{K}=2)$, north and south of the Rift Valley (Supplementary Fig. S3-S4). There were no further splits within each cluster. There was some evidence of allele sharing between both sides of the Rift Valley (Fig. 3c). $\mathrm{F}_{\mathrm{ST}}$ and Jost's D values were strongly correlated (MRDM: $\mathrm{R}^{2}=0.684, \mathrm{P}=0.018$ ). In both cases, values confirmed the separation between populations north and south of the Rift Valley, with low values between the two Bale populations south of the valley and highest values between populations on either side of the Rift Valley (Supplementary Table S5).

Based on the mtDNA dataset, the Bale-S population had highest nucleotide diversity, substantially higher than the rest of the populations. The Simien population had lowest nucleotide diversity, but the highest haplotype diversity, though differences in haplotype diversity between populations were negligible (Table 2). Based on the microsatellite dataset, all populations had relatively high and similar levels of genetic diversity, with a particularly high number of private alleles identified in the Guassa population. Abune Yosef and Bale-S had the highest levels of inbreeding, while Simien and Guassa had the lowest, though all values were low (Table 2).

Allelic richness corrected for sample size decreased as the proportion of arable land in $5 \mathrm{~km}$ radius around the population capture location increased $\left(\mathrm{F}=10.41, \mathrm{df}=1,3, \mathrm{P}=0.048, \mathrm{R}^{2}=0.717\right.$; Supplementary Fig. S5). Levels of inbreeding did not relate to any of the land-use variables (Supplementary Table S6). 


\section{Landscape barriers to gene flow}

The topographic hypothesis (effect of altitude) had the strongest support (AICcmin=0.501, BICew=0.475), followed by the ecoregions hypothesis $(\mathrm{AICcmin}=0.412, \mathrm{BICew}=0.303)$. Confidence intervals of both variables did not overlap zero, supporting their effect on gene flow (Table 3). The exact same hypotheses received the strongest support based on Jost's D measure of genetic differentiation, though the ecoregions hypothesis received the highest support (Supplementary Table S7). Projected movement density maps based on the effect of these two landscape variables highlight the strong effect of the Rift Valley on genetic connectivity in $P$. balensis and the split between populations to the north and south of the valley (Fig. 4). The remaining hypotheses had very low support. Hypotheses that included multiple variables had little support, likely due to the small number of nodes (Table 3).

\section{Demographic history}

The best-supported scenario was of a recent approximately six-fold decline of the south-eastern population but no change in the north-western population (scenario 4; probability of scenario 0.988 , overall model error $<0.001$, type 1 error $=0.095$, type 2 error averaged over scenarios $( \pm$ standard deviation $)=0.046 \pm 0.04$; Supplementary Fig. S6; Table S8). Model checking for the most probably scenario (scenario 4) indicated a good fit between observed and simulated datasets, whereby the observed dataset fell within the cloud of simulated points (Supplementary Fig. S7). Rift valley split time was estimated at a median of 89,600 years ago (95\% CI: 35,000-155,400), based on a generation time of two years, while the decline of the south-eastern population was estimated to have occurred at a median of 150 years ago (95\% CI: 30-1000). Bias in parameter estimation was low (mean relative bias 0.18-0.26 for population size parameters, and 0.29 for time of decline of southern population; Table 4).

\section{Discussion}

Through combining ecological niche modelling, ABC inference of demographic history and landscape genetics we show how historic climatic changes during the Quaternary have shaped the population structure and patterns of genetic variation of the biodiversity in Afromontane and Afroalpine sky islands. We further show the impact of recent anthropogenic land-use change and habitat degradation on population declines and loss of genetic diversity in species that are also threatened by disappearing suitable niche under future climate change in one of the most endemism rich and endangered ecosystem in the world (Williams et al., 2004).

\section{Effects of climate change past and future}

Ecological niche models support the restricted distribution of P. balensis in Afroalpine moorland and Afromontane grassland and woodland high elevation regions of the Ethiopian highlands, and show that its distribution is primarily limited by temperatures. Models projected across temporal scales show that climatic suitability for $P$. balensis has been progressively decreasing since the LGM and will continue to decrease with increasing temperatures over the next few decades, with a direct effect on population fragmentation and isolation. The genus Plecotus is of Palearctic origin and is found primarily across temperate and Mediterranean habitats (Spitzenberger et al., 2006). As such, it is not surprising that climatic conditions in the tropics were more suitable for this bat when temperatures were lower during the LGM. Increased climatic suitability during LGM and displacement of the Afroalpine and ericaceous zone to lower elevations (Bonnefille, Roeland, \& Guiot, 1990) allowed high altitude species to extend their range (Gottelli, Marino, Sillero-Zubiri, \& Funk, 2004) and likely led to contact between isolated sky island populations (McCormack et al., 2009). This can explain the observed limited differentiation between mountain ranges not separated by the substantially lower Rift Valley. 
Sky islands are sensitive to future climate change because the high montane and alpine habitats could contract into higher elevations with even minor temperature increases, reducing the habitat available for their associated endemic taxa (McCormack et al., 2009). Tropical montane forests, in particular, are some of the most threatened habitats under climate warming (Moritz \& Agudo, 2013). Tropical montane regions are predicted to experience highest levels of disappearing climates, and consequently species extinctions and community disruptions (Williams, Jackson, \& Kutzbach, 2007). In Ethiopia, Nyssen et al. (2014) already identified evidence of upper shifts of the high elevation treeline in response to climatic changes in the past century. This ecotone is located between the Afromontane and Afroalpine zones and is particularly rich in biodiversity (Kidane et al., 2012). Indeed our models predict that only a quarter of the current range of $P$. balensis will remain climatically suitable by the end of the century. These predictions are relevant to other high altitude Afromontane biodiversity, and therefore are particularly worrying given the high levels of endemism found in this ecoregion, in particular among vertebrates (Williams et al., 2004) and vascular plants (Gizaw et al., 2016).

\section{Effects of geographical barriers - Rift Valley and sky islands}

The Ethiopian Rift Valley was identified as the main barrier to contemporary gene flow shaping the population structure of $P$. balensis . The Great Rift Valley, extending from Lebanon through the Red Sea to the Zambezi River, is less than $100 \mathrm{~km}$ wide across the Ethiopian central highlands (Ebinger et al., 2000), dividing them into two massifs from northwest to southeast. It played a major role in structuring biodiversity across Eastern Africa, from the Afroalpine plantsArabis alpine (Asefa, Ehrich, Taberlet, Nemomissa, \& Brochmann, 2007) and Lobelia giberroa (Kebede, Ehrich, Taberlet, Namomissa, \& Brochmann, 2007) to most of Ethiopian anurans (Freilich et al., 2016), including the high altitude African clawed frogs, Xenopussp. (Evans, Bliss, Mendel, \& Tinsley, 2011) and the forest tree frogs (Reyes-Velasco et al., 2018). Interestingly, amphibians found at elevations below 2500 masl did not show differences between the northern and southern highland massifs (Freilich et al., 2016). As P. balensis is associated with low temperatures and montane ecosystems above $2000 \mathrm{~m}$ (Benda et al., 2004), the much warmer and drier savannah-like habitats at low elevation along the Rift Valley are very likely to be inhospitable for this bat. In fact, according to our data, the main split along the Rift Valley, can be traced to the last interglacial period when conditions were even warmer and drier than in the Holocene (Adams, Maslin, \& Thomas, 1999). Evidence of limited allele sharing between both sides of the Rift Valley is most probably related to the short time that elapsed since the last contact between Afromontane habitats across the Rift Valley, rather than present day gene flow.

The complex geological history of the Ethiopian highlands is partially responsible for its high biodiversity and endemism. The highlands do not constitute a single unit, but instead are formed by various massifs of different areas, origins, ages and degrees of isolation (Reyes-Velasco et al., 2018). Genomic differentiation in highland species, like the river frog, Amietia nutti, is explained not only by the Rift Valley but also by other major geographical barriers, the Blue Nile Valley and the Omo River (Manthey, Reyes-Velasco, Freilich, \& Boissinot, 2017). This geographical and historical complexity is expected to affect the phylogeography of $P$. balensis. The isolation of sky islands is supported by the deep genetic structure found in the mtDNA markers and the fact no haplotypes were shared between mountain ranges and all mountain ranges formed separate clades in the mtDNA tree. All clades, except the Bale population that included deeply divergent basal lineages, could be the result of isolation processes relating to older glacial cycles during the Pleistocene. These episodes of allopatric isolation appear as the main driver of differentiation in Ethiopian highland vertebrates (Reyes-Velasco et al., 2018). The phylogeographic structure of $P$. balensis is consistent with that of the Ethiopian wolf (Gottelli et al., 2004), whereby three main clusters are present corresponding to the three well-defined mountain areas: the southern Chilalo/Bale, the central Guassa/Abune Yosef and the northern isolated Siemen Massifs. This strong structure at the mtDNA level indicates that sky islands have acted as historic barriers to gene flow in P. balensis. Sky islands are strong isolating mechanism in limited dispersal species. For example, the endemic high altitude spider Microhexura montivaga in the southern Appalachians is divided into separate clades corresponding to mountain ranges, though this species shows strong population subdivision also at the nuclear level (Hedin, Carlson, \& Coyle, 2015). In contrast, in 
P. balensis the nuclear microsatellite dataset only identified a split into two clusters, corresponding to the populations on either side of the Rift Valley.

More limited population structure based on bi-parentally inherited markers suggests that gene flow between mountain ranges is primarily male-mediated, a common pattern in temperate bat species (Moussy et al., 2013; Razgour, Salicini, Ibáñez, Randi, \& Juste, 2015). However, as extensive contemporary gene flow between mountain ranges is unlikely given the extent of habitat conversion across the Ethiopian highlands (Lemenih \& Kassa, 2014), the shallow genetic structure at the nuclear level, may instead indicate habitat connectivity during the Holocene, possibly through montane forest bridges during episodes of increased moisture (Umer et al., 2007). However, other Ethiopian highland species do show strong structure and limited gene flow in bi-parentally inherited markers, including the mountain nyala (Atickem et al., 2013) and Ethiopian wolf, in which current gene flow is limited to geographically close populations (Gottelli, Sillero-Zubiri, Marino, Funk, \& Wang, 2013). Alternatively, genetic differentiation may be driven by local adaptations and environmental dissimilarity and therefore its signature cannot be identified in neutral markers (Manthey \& Moyle, 2015).

\section{Effects of anthropogenic land-use change}

Although ENMs identified that P. balensis is primarily associated with Afroalpine moorland and grassland and Afromontane woodland ecoregions, reproductive females and sub-adults were only found in high altitude Afromontane woodlands, highlighting the importance of this habitat for the species' reproductive success. A similar pattern of elevational segregation was observed in other Palearctic bats such as the European noctules (Ibanez et al., 2009) and the congeneric alpine long-eared bat Plecotus macrobullaris (Alberdi, Aizpurua, Aihartza, \& Garin, 2014), whereby maternity colonies in colder regions of the distribution are found below the treeline. Alberdi et al. (2014) attribute this segregation to restrictions on facultative heterothermy and use of torpor in pregnant and lactating females.

The Afromontane woodland habitat is highly threatened and disappearing due to extensive deforestation and overgrazing (Yalden et al., 1996). Deforestation rates in the Ethiopian Highlands are severe following centuries of landscape changes due to subsistence farming, settlement and demands for fuelwood (Lemenih \& Kassa, 2014). Native forest cover has declined in the past 100 years from $45 \%$ to only $5 \%$ of the country, and currently most of the native forest cover in the highlands is concentrated in small patches surrounding orthodox churches, known as church forests (Abbott, 2019). The mountain forest belt has been pushed upwards and fragmented due to extensive agriculture (Kebede et al., 2007). Some of the forests where bats were caught south of the Rift Valley were degraded, fragmented and showed limited evidence of recruitment due to overgrazing of ground vegetation cover. This represents a broader trend of forest degradation in the Bale Mountains region, including inside the National Park, due to logging, fuelwood collection and livestock grazing (Asefa, Mengesha, Shimelis, \& Mamo, 2015), which has been linked with the recent declines of most large wild mammals populations within the park (Stephens et al., 2001).

The recent decline of the south-eastern P. balensis population identified in our ABC model-based inference appears to coincide with a period of accelerated forest loss and degradation and the expansion of agriculture, though causal mechanisms behind the decline were not tested here. No evidence of decline in the northwestern population could be attributed to the general higher density of montane forests in the wetter north, as well as the buffering effect of the thousands of church forests containing native trees that are spread across the north-western highlands (Klepeis et al., 2016). However, small sample sizes may have limited the inference power of the $\mathrm{ABC}$ analysis when it comes to identifying more moderate bottlenecks. Genetic diversity in the Ethiopian wolf was also higher in the northern highlands (Gottelli et al., 2004), indicating that habitat degradation in the south is having a detrimental effect on Afroalpine and Afromontane mammals in general. Although native forest loss has been more limited in the northern highlands over the past 150 years, degradation is on-going in the more recently settled Simien mountains (Nyssen et al., 2014), suggesting that the northern highlands Afromontane biodiversity is also at risk.

Despite the strong effect of anthropogenic land-use change on genetic diversity and population decline in $P$. 
balensis, indicators of anthropogenic impact, like artificial lights at night and human footprint index, did not affect gene flow. Low sample size (five populations) may have reduced the power of the landscape genetics statistical analysis, in particular when considering the combined impact of more than one variable, and therefore this limitation may have obscured the importance of some drivers of landscape resistance. Although native church forest patches and small community-managed forest reserves offer some level of landscape connectivity across the agricultural and human settlement landscape, percent tree cover did not affect genetic connectivity. However, this may be attributed to the tree cover map used, which does not distinguish between native forests and eucalyptus plantations (Hansen et al., 2013), and therefore could not capture the effect of the landscape on the movement of $P$. balensis . Instead, the landscape genetics analysis highlights the importance of altitude and Afroalpine and Afromontane habitats. The best-supported model gave lowest resistance costs to the high altitude alpine moorland ecoregion, rather than the montane forest ecoregion, perhaps due to the more restricted distribution of native montane forest than the ecoregion classification suggests because of extensive deforestation in the past century. Alternatively, this may reflect temperature or other climatic limitations on the movement of $P$. balensis, as is the case with other cold-adapted high altitude mammals, like the American pika, Ochotona princeps (Castillo, Epps, Davis, \& Cushman, 2014). Altitude was also identified as the main landscape element limiting gene flow in high altitude salamanders, alongside pond network structure. However, genetic connectivity in these more limited dispersal species was primarily affected by geographic distance presumably due to the rarity of dispersal events in the extreme high altitude environment (Savage, Fremier, \& Bradley, 2010).

\section{Conclusions}

Using a combination of ecological niche models, landscape genetics and $\mathrm{ABC}$ model-based inference of demographic history we show how historic climate change and geographic barriers interact with recent anthropogenic habitat loss and degradation to shape the population size, structure, diversity and connectivity of tropical montane biodiversity. Focusing on the endemic Ethiopian Highlands bat, P. balensis, we found that despite strong associations with high altitude environments and mtDNA pattern associated with sky island structure, some level of genetic connectivity is maintained among sky islands, and only substantially lower altitudes, like the Rift Valley, form a true barrier to gene flow. Of particular concern are evidence of recent population decline, likely in response to deforestation and land conversion, the decline in genetic diversity with increasing arable land cover, and the importance of Afroalpine and Afromontane ecoregions for both range suitability and genetic connectivity between sky islands. Given that similar patterns of genetic population structure have been recorded in other high altitude mammals and amphibians, such losses of genetic diversity and population declines may be widespread in tropical montane ecosystems. The situation described for this bat epitomises a wider trend in high altitude Afromontane and Afroalpine biodiversity, which is under threat from extensive deforestation, agricultural conversion and overgrazing following rapid human population expansion (Yalden et al., 1996). These threats are not likely to be reversed in the future in countries like Ethiopia where accelerated human population growth is projected to continue until the end of the century (UN, 2019). These immediate threats will interact with future climate change and the projected disappearance of suitable climates and their associated ecoregions in tropical montane regions (Williams et al., 2007), which will increase the likelihood of extinction of high altitude species. This study presents alarming predictions for the fate of tropical montane and alpine biodiversity, projected to be squeezed to higher altitudes (or even disappear) due to climate change while already losing genetic diversity and suffering population declines due to anthropogenic land-use change. The combination of these different threats can push these ecosystems beyond their resilience limits. We conclude that assessments of threats to biodiversity under global change should adopt a holistic approach, simultaneously studying the effects of multiple threats and considering the impacts of past events, present stressors and future projections based on genetic, ecological and geographic information. 


\section{Acknowledgements}

This project was funded through a British Ecological Society Research grant (4849/5889) and Severo Ochoa grants (MicroP_SO_14 and MicroProy_SO_15) from the EBD-CSIC. OR was funded through a Natural Environment Research Council Independent Research Fellowship (NE/M018660/1) and University of Stirling Impact Fellowship. We are grateful to Neguse Engda, Ziyad Jemal and Dessiew Gelaw for help with fieldwork, and Laura Kubasiewicz and Juan Luis Garcia-Mudarra of the Molecular Ecology lab LEM-EBD for carrying out the lab work. Research and export permits were granted by the Ethiopian Wildlife Conservation Authority (EWCA) with the help of Prof Afework Bekele (Addis Ababa University). We thank the wardens and experts of Bale Mountains National Park, Arsi Mountains National Park, Simien Mountains National Park, Aboy Gara Community Conservation and Guassa Community Based Conservation Area. The following people and organisations facilitated the fieldwork in Ethiopia: Isabel Cantero (CSIC and Addis Ababa University), Claudio Sillero and the Ethiopian Wolf Conservation project, Karen Laurenson and Frankfurt Zoological Society-Ethiopia (FZS-ETH), Spanish Embassy in Ethiopia, Guy and Yvonne Levene of Bale Mountain Lodge, Guassa Lodge, and Manner Tour Car Rental and car drivers.

\section{References}

Abbott, A. (2019). Biodiversity thrives in Ethiopia's church forests.Nature , 565 , 548-549.

Adams, J., Maslin, M., \& Thomas, E. (1999). Sudden climate transitions during the Quaternary. Progress in Physical Geography: Earth and Environment, 23 (1), 1-36.

Alberdi, A., Aizpurua, O., Aihartza, J., \& Garin, I. (2014). Unveiling the factors shaping the distribution of widely distributed alpine vertebrates, using multi-scale ecological niche modelling of the bat Plecotus macrobullaris. Frontiers in Zoology , 11 (1), 77.

Asefa, A., Mengesha, G., Shimelis, A., \& Mamo, Y. (2015). Livestock grazing in Afromontane grasslands in the northern Bale Mountains, Ethiopia: Implications for bird conservation. Science, Technology and Arts Research Journal , 4 (2), 112-121.

Asefa, A., Ehrich, D., Taberlet, P., Nemomissa, S., \& Brochmann, C. (2007). Pleistocene colonization of afro-alpine 'sky islands' by the arctic-alpine Arabis alpina. Heredity , 99 (2), 133-142.

Atickem, A., Rueness, E. K., Loe, L. E., Serbezov, D., Bekele, A., \& Stenseth, N. C. (2013). Population genetic structure and connectivity in the endangered Ethiopian mountain Nyala (Tragelaphus buxtoni): recommending dispersal corridors for future conservation.Conservation Genetics , 14 (2), 427-438.

Bates, D., Machler, M., Bolker, B., \& Walker, S. (2015). Fitting linear mixed-effects models using lme4. Journal of Statistical Software ,67 (1), 1-48.

Benda, P., Kiefer, A., Hanak, V., \& Veith, M. (2004). Systematic status of African populations of long-eared bats, genus Plecotus (Mammalia: Chiroptera). Folia Zoologica, 53 , 47.

Bonnefille, R., Roeland, J. C., \& Guiot, J. (1990). Temperature and rainfall estimates for the past 40,000 years in equatorial Africa.Nature , $346,347-349$.

Castillo, J. a, Epps, C. W., Davis, A. R., \& Cushman, S. a. (2014). Landscape effects on gene flow for a climate-sensitive montane species, the American pika. Molecular Ecology , 843-856.

Cornuet, J.-M., Pudlo, P., Veyssier, J., Dehne-Garcia, A., Gautier, M., Leblois, R., ... Estoup, A. (2014). DIYABC v2.0: a software to make approximate Bayesian computation inferences about population history using single nucleotide polymorphism, DNA sequence and microsatellite data. Bioinformatics , 30 (8), $1187-1189$. 
Cornuet, J.-M., Ravigne, V., \& Estoup, A. (2010). Inference on population history and model checking using DNA sequence and microsatellite data with the software DIYABC (v1.0). BMC Bioinformatics , 11 , 401.

Darriba, D., Taboada, G. L., Doallo, R., \& Posada, D. (2012). jModelTest 2: more models, new heuristics and parallel computing. Nature Methods , 9 (8), 772-772.

Earl, D. A., \& vonHoldt, B. M. (2012). STRUCTURE HARVESTER: a website and program for visualizing STRUCTURE output and implementing the Evanno method. Conservation Genetics Resources , 4 (2), 359-361.

Ebinger, C. J., Yemane, T., Harding, D. J., Tesfaye, S., Kelley, S., \& Rex, D. C. (2000). Rift deflection, migration, and propagation: Linkage of the Ethiopian and Eastern rifts, Africa. Geological Society of America Bulletin , 112 (2), 163-176.

Evans, B. J., Bliss, S. M., Mendel, S. A., \& Tinsley, R. C. (2011). The Rift Valley is a major barrier to dispersal of African clawed frogs (Xenopus) in Ethiopia. Molecular Ecology , 20 (20), 4216-4230.

Flanders, J., Jones, G., Benda, P., Dietz, C., Zhang, S., Li, G., .. Rossiter, S. J. (2009). Phylogeography of the greater horseshoe bat, Rhinolophus ferrumequinum: contrasting results from mitochondrial and microsatellite data. Molecular Ecology , 18 (2), 306-318.

Fourcade, Y., Engler, J. O., Rodder, D., \& Secondi, J. (2014). Mapping Species Distributions with MAXENT Using a Geographically Biased Sample of Presence Data: A Performance Assessment of Methods for Correcting Sampling Bias. PLoS ONE , 9 (5), e97122.

Freilich, X., Anadon, J. D., Bukala, J., Calderon, O., Chakraborty, R., \& Boissinot, S. (2016). Comparative phylogeography of Ethiopian anurans: impact of the Great Rift Valley and Pleistocene climate change. $B M C$ Evolutionary Biology , 16 , 206.

Gizaw, A., Brochmann, C., Nemomissa, S., Wondimu, T., Masao, C. A., Tusiime, F. M., ... Dimitrov, D. (2016). Colonization and diversification in the African 'sky islands': insights from fossil-calibrated molecular dating of Lychnis (Caryophyllaceae).New Phytologist, 211 (2), 719-734.

Goslee, S. C., \& Urban, D. L. (2007). The ecodist Package for Dissimilarity-based Analysis of Ecological Data. Journal of Statistical Software, 22 (7), 1-19.

Gottelli, D., Marino, J., Sillero-Zubiri, C., \& Funk, S. M. (2004). The effect of the last glacial age on speciation and population genetic structure of the endangered Ethiopian wolf (Canis simensis).Molecular Ecology , 13 (8), 2275-2286.

Gottelli, D., Sillero-Zubiri, C., Marino, J., Funk, S. M., \& Wang, J. (2013). Genetic structure and patterns of gene flow among populations of the endangered Ethiopian wolf. Animal Conservation , 16 (2), 234-247.

Goudet, J. (1995). FSTAT (version 1.2): a computer program to calculate F-statistics. Journal of Heredity , $86(6), 485-486$.

Gower, D. J., Aberra, R. K., Schwaller, S., Largen, M. J., Collen, B., Spawls, S., .. Loader, S. P. (2013). Long-term data for endemic frog genera reveal potential conservation crisis in the Bale Mountains, Ethiopia. Oryx , 47 (1), 59-69.

Hall, T. (1999). BioEdit: a user-friendly biological sequence alignment editor and analysis program for Windows 95/98/NT. Nucleic Acids Symposium Series , 41 (41), 95-98.

Hansen, M. C., Potapov, P. V., Moore, R., Hancher, M., Turubanova, S. A., Tyukavina, A., .. et al. (2013). High-resolution global maps of 21st century forest cover change. Science (New York, N.Y.) ,342 (6160), 850-853.

Hardy, O. J., \& Vekemans, X. (2002). SPAGeDi: a versatile computer program to analyse spatial genetic structure at the individual or population levels. Molecular Ecology Notes , 2 (4), 618-620. 
Harmsen, R., Spence, J. R., \& Mahaney, W. C. (1991). Glacial interglacial cycles and development of the Afroalpine ecosystem on East African Mountains II. Origins and development of the biotic component.Journal of African Earth Sciences , 12 (3), 513-523.

Hedberg, O. (1969). Evolution and speciation in a tropical high mountain flora. Biological Journal of the Linnean Society , 1 (1-2), 135-148.

Hedin, M., Carlson, D., \& Coyle, F. (2015). Sky island diversification meets the multispecies coalescent divergence in the spruce-fir moss spider ( Microhexura montivaga, Araneae, Mygalomorphae) on the highest peaks of southern Appalachia. Molecular Ecology ,24 (13), 3467-3484.

Hewitt, G. (2000). The genetic legacy of the Quaternary ice ages.Nature , 405 (6789), 907-913.

Hillman, J. C. (1986). Conservation in Bale Mountains National Park, Ethiopia. Oryx , 20 (2), 89-94.

Hoban, S., Gaggiotti, O., \& Bertorelle, G. (2013). Sample Planning Optimization Tool for conservation and population Genetics (SPOTG): a software for choosing the appropriate number of markers and samples. Methods in Ecology and Evolution , 4 (3), 299-303.

Ibanez, C., Garcia-Mudarra, J. L., Ruedi, M., Stadelmann, B., \& Juste, J. (2006). The Iberian contribution to cryptic diversity in European bats. Acta Chiropterologica , 8 (2), 277-297.

Ibanez, C., Guillen, A., Agirre-Mendi, P. T., Juste, J., Schreur, G., Cordero, A. I., \& Popa-Lisseanu, A. G. (2009). Sexual Segregation in Iberian Noctule Bats. Journal of Mammalogy , 90 (1), 235-243.

IPCC. (2013). Climate change 2013 : the physical science basis : Working Group I contribution to the Fifth assessment report of the Intergovernmental Panel on Climate Change (T. Stocker, D. Qin, G.-K. Plattner, \& et al., eds.). Cambridge, UK and New York, USA: Cambridge University Press.

Jones, G., Jacobs, D. S., Kunz, T. H., Willig, M. R., \& Racey, P. A. (2009). Carpe noctem: the importance of bats as bioindicators. Endangered Species Research , 8 , 93-115.

Jost, L. (2008). G ST and its relatives do not measure differentiation. Molecular Ecology , 17 (18), 4015-4026.

Juste, J., Ibanez, C., Munoz, J., Trujillo, D., Benda, P., Karataş, A., \& Ruedi, M. (2004). Mitochondrial phylogeography of the long-eared bats (Plecotus) in the Mediterranean Palaearctic and Atlantic Islands. Molecular Phylogenetics and Evolution, 31 (3), 1114-1126.

Kalinowski, S. T., Taper, M. L., \& Marshall, T. C. (2007). Revising how the computer program cervus accommodates genotyping error increases success in paternity assignment. Molecular Ecology , 16 (5), 1099-1106.

Kebede, M., Ehrich, D., Taberlet, P., Namomissa, S., \& Brochmann, C. (2007). Phylogeography and conservation genetics of a giant lobelia (Lobelia giberroa) in Ethiopian and Tropical East African mountains. Molecular Ecology , 16 (6), 1233-1243.

Kidane, Y., Stahlmann, R., \& Beierkuhnlein, C. (2012). Vegetation dynamics, and land use and land cover change in the Bale Mountains, Ethiopia. Environmental Monitoring and Assessment ,184 (12), 7473-7489.

Kingdon, J. (1990). Island Africa : the evolution of Africa's rare animals and plants .

Klepeis, P., Orlowska, I. A., Kent, E. F., Cardelús, C. L., Scull, P., Wassie Eshete, A., \& Woods, C. (2016). Ethiopian church forests: A hybrid model of protection. Human Ecology , 44 (6), 715-730.

Kruskop, S. V., \& Laverenchenko, L. A. (2000). A new species of long-eared bat (Plecotus; Vespertilionidae, Mammalia) from Ethiopia.Myotis , 38, 5-17.

Lawler, J. J., Shafer, S. L., White, D., Kareiva, P., Maurer, E. P., Blaustein, A. R., \& Bartlein, P. J. (2009). Projected climate-induced faunal change in the Western Hemisphere. Ecology , 90 (3), 588-597. 
Lemenih, M., \& Kassa, H. (2014). Re-greening Ethiopia: history, challenges and lessons. Forests , 5 (8), 1896-1909.

Librado, P., \& Rozas, J. (2009). DnaSP v5: a software for comprehensive analysis of DNA polymorphism data. Bioinformatics , 25 (11), 1451-1452.

Liu, C., White, M., \& Newell, G. (2013). Selecting thresholds for the prediction of species occurrence with presence-only data. Journal of Biogeography , 40 (4), 778-789.

Manthey, J. D., \& Moyle, R. G. (2015). Isolation by environment in White-breasted Nuthatches ( Sitta carolinensis ) of the Madrean Archipelago sky islands: a landscape genomics approach. Molecular Ecology, 24 (14), 3628-3638.

Manthey, J. D., Reyes-Velasco, J., Freilich, X., \& Boissinot, S. (2017). Diversification in a biodiversity hotspot: genomic variation in the river frog Amietia nutti across the Ethiopian Highlands. Biological Journal of the Linnean Society , 122 (4), 801-813.

McCormack, J. E., Huang, H., \& Knowles, L. L. (2009). Sky islands. In R. G. Gillespie \& D. A. Clague (Eds.), Encyclopedia of Islands (pp. 841-843).

McRae, B. H. (2006). Isolation by resistance. Evolution ,60 (8), 1551.

Moritz, C., \& Agudo, R. (2013). The future of species under climate change: resilience or decline? Science, 341 (6145), 504-508.

Moussy, C., Hosken, D. J., Mathews, F., Smith, G. C., Aegerter, J. N., \& Bearhop, S. (2013). Migration and dispersal patterns of bats and their influence on genetic structure. Mammal Review ,43 (3), 183-195.

Naimi, B., Hamm, N. A. S., Groen, T. A., Skidmore, A. K., \& Toxopeus, A. G. (2014). Where is positional uncertainty a problem for species distribution modelling? Ecography , 37 (2), 191-203.

Nyssen, J., Frankl, A., Haile, M., Hurni, H., Descheemaeker, K., Crummey, D., .. P Poesen, J. (2014). Environmental conditions and human drivers for changes to north Ethiopian mountain landscapes over 145 years. Science of The Total Environment ,485-486 , 164-179.

Olson, D. M., Dinerstein, E., Wikramanayake, E. D., Burgess, N. D., Powell, G. V. N., Underwood, E. C., ... Kassem, K. R. (2001). Terrestrial Ecoregions of the World: A New Map of Life on Earth.BioScience , 51 (11), 933-938.

Peakall, R., \& Smouse, P. E. (2006). GENALEX 6: genetic analysis in Excel. Population genetic software for teaching and research. Molecular Ecology Notes , 6 (1), 288-295.

Phillips, S. J., Anderson, R. P., \& Schapire, R. E. (2006). Maximum entropy modeling of species geographic distributions. Ecological Modelling , 6 (2-3), 231-252.

Pimm, S. L. (2009). Climate disruption and biodiversity. Current Biology , 19 (14), R595-R601.

Pritchard, J. K., Stephens, M., \& Donnelly, P. (2000). Inference of population structure using multilocus genotype data. Genetics ,155 (2), 945-959.

Razgour, O., Rebelo, H., Puechmaille, S. J., Juste, J., Ibáñez, C., Kiefer, A., .. Jones, G. (2014). Scaledependent effects of landscape variables on gene flow and population structure in bats.Diversity and Distributions , 20 (10), 1173-1185.

Razgour, O., Salicini, I., Ibáñez, C., Randi, E., \& Juste, J. (2015). Unravelling the evolutionary history and future prospects of endemic species restricted to former glacial refugia. Molecular Ecology ,24 (20), $5267-5283$.

Razgour, Orly, Hanmer, J., \& Jones, G. (2011). Using multi-scale modelling to predict habitat suitability for species of conservation concern: The grey long-eared bat as a case study. Biological Conservation , 144 
(12), 2922-2930.

Razgour, Orly, Juste, J., Ibáñez, C., Kiefer, A., Rebelo, H., Puechmaille, S. J., .. Jones, G. (2013). The shaping of genetic variation in edge-of-range populations under past and future climate change. Ecology Letters , 16 , 1258-1266.

Reyes-Velasco, J., Manthey, J. D., Freilich, X., \& Boissinot, S. (2018). Diversification of African tree frogs (genus Leptopelis ) in the highlands of Ethiopia. Molecular Ecology , 27 (9), 2256-2270.

Ronquist, F., Teslenko, M., van der Mark, P., Ayres, D. L., Darling, A., Höhna, S., ... Huelsenbeck, J. P. (2012). MrBayes 3.2: Efficient Bayesian phylogenetic inference and model choice across a large model space. Systematic Biology , 61 (3), 539-542.

Rosenberg, N. A. (2003). DISTRUCT: a program for the graphical display of population structure. Molecular Ecology Notes , 4 (1), 137-138.

Rousset, F. (2008). GENEPOP'007: a complete re-implementation of the genepop software for Windows and Linux. Molecular Ecology Resources , 8 (1), 103-106.

Savage, W. K., Fremier, A. K., \& Bradley, S. H. (2010). Landscape genetics of alpine Sierra Nevada salamanders reveal extreme population subdivision in space and time. Molecular Ecology , 19 (16), 3301-3314.

Smith, M. F., \& Patton, J. L. (1993). The diversification of South American murid rodents: evidence from mitochondrial DNA sequence data for the akodontine tribe. Biological Journal of the Linnean Society , 50 (3), 149-177.

Spitzenberger, F., Strelkov, P. P., Winkler, H., \& Haring, E. (2006). A preliminary revision of the genus Plecotus (Chiroptera, Vespertilionidae) based on genetic and morphological results.Zoologica Scripta , 35 (3), 187-230.

Stephens, P. A., d'Sa, C. A., Sillero-Zubiri, C., \& Leader-Williams, N. (2001). Impact of livestock and settlement on the large mammalian wildlife of Bale Mountains National Park, southern Ethiopia.Biological Conservation, 100 (3), 307-322.

Umer, M., Lamb, H. F., Bonnefille, R., Lézine, A.-M., Tiercelin, J.-J., Gibert, E., .. Watrin, J. (2007). Late Pleistocene and Holocene vegetation history of the Bale Mountains, Ethiopia. Quaternary Science Reviews , 26 (17-18), 2229-2246.

UN. (2019). World Population Prospects. DESA Population Division. https://population.un.org/wpp/ Accessed 01.08.2019.

Van Strien, M. J., Keller, D., \& Holderegger, R. (2012). A new analytical approach to landscape genetic modelling: least-cost transect analysis and linear mixed models. Molecular Ecology ,21 (16), 4010-4023.

Wang, J. (2011). COANCESTRY: a program for simulating, estimating and analysing relatedness and inbreeding coefficients. Molecular Ecology Resources , 11 (1), 141-145.

Warren, D. L., Glor, R. E., \& Turelli, M. (2010). ENMTools: A toolbox for comparative studies of environmental niche models. Ecography ,33 (3), 607-611.

Wilkinson, G. S., \& Chapman, A. M. (1991). Length and sequence variation in evening bat D-loop mtDNA. Genetics , 128 (3), 607-617.

Williams, J. W., Jackson, S. T., \& Kutzbach, J. E. (2007). Projected distributions of novel and disappearing climates by 2100 AD.Proceedings of the National Academy of Sciences of the United States of America, 104 (14), 5738-5742.

Williams, S. D., Vivero, J. L., Spawls, S., Anteneh, S., \& Ensermu, K. (2004). Ethiopian Highlands. In R. A. Mittermeier, P. Robles-Gil, M. Hoffmann, J. D. Pilgrim, T. M. Brooks, C. G. Mittermeier, \& G. Fonseca (Eds.), Hotspots Revisited: Earth's Biologically Richest and Most Endangered Ecoregions (pp. 262-273). 
Xia, X., \& Xie, Z. (2001). DAMBE: Software Package for Data Analysis in Molecular Biology and Evolution. Journal of Heredity ,92 (4), 371-373.

Yalden, D. W., Largen, M. J., Kock, D., \& Hillman, J. C. (1996). Catalogue of the mammals of Ethiopia and Eritrea. 7. Revised checklist, zoogeography and conservation. Tropical Zoology , 9 (1), 73-164.

\section{Data Accessibility}

- DNA sequences will be submitted to Genbank.

- Microsatellite dataset, mtDNA sequence assembly, Maxent output files and STRUCTURE results will be made available through Dryad.

- Sampling locations uploaded as Supplementary Table S1.

\section{Author Contribution}

OR and JJ conceived and designed the study. OR, MK, HS and JJ collected the samples. OR and JJ carried out the lab work. OR performed the data analysis and modelling. OR and JJ wrote the manuscript and all authors contributed to revisions.

Table 1 - Projected range changes for Plecotus balensisfrom the last glacial maximum (LGM) until the end of the century (2070). Presented values are from the ensemble ENMs with range of values from models generated with the different GCMs in brackets. Percent range change indicate the percent by which the present suitable range has increased or decreased under projections for different time scales.

\begin{tabular}{llll}
\hline Model & Suitable cells & \% horn of Africa suitable & \% range change \\
\hline Present & 18036 & 0.76 & \\
Future (2070; RCP 8.5) & 4623 & $0.19(0.11-0.22)$ & $-74.4(71.3-85.5)$ \\
Future (2070; RCP 4.5) & 6832 & $0.29(0.25-0.36)$ & $-62.1(52.7-67.4)$ \\
LGM & 81815 & $3.54(2.82-4.01)$ & $353.6(263.6-410.1)$ \\
Mid-Holocene & 68065 & $2.93(1.86-3.69)$ & $277.4(142.4-372.3)$ \\
\hline
\end{tabular}

Table 2 - Population genetics summary statistics for Plecotus balensis . Columns 3-6 include mean number of alleles (Na), allelic richness corrected for sample size (Ar), number of private alleles $(\mathrm{Pa})$ and average inbreeding (TrioML) per population for the microsatellite dataset. Columns 7-9 show number of haplotypes (Hap), haplotype diversity $(\mathrm{Hd})$ and nucleotide diversity (Pi) per population for the mitochondrial DNA (concatenated Cytb and HVI sequences) dataset. ( $\mathrm{N}=$ sample size).

\begin{tabular}{lllllllll}
\hline Population & $\mathbf{N}$ & $\mathbf{N a}$ & Ar & Pa & TrioML & Hap & Hd & Pi \\
\hline Bale-D & 7 & 5.579 & 5.286 & 11 & 0.066 & 6 & 0.952 & 0.0065 \\
Bale-S & 9 & 6.737 & 5.694 & 17 & 0.081 & 8 & 0.972 & 0.0297 \\
Guassa & 7 & 6.368 & 5.139 & 26 & 0.055 & 5 & 0.857 & 0.0061 \\
Simien & 12 & 6.105 & 5.605 & 16 & 0.051 & 11 & 0.985 & 0.0029 \\
Abune & 11 & 6.632 & 5.907 & 14 & 0.096 & 8 & 0.972 & 0.0065 \\
\hline
\end{tabular}

Table 3 - Results of the MLPE landscape genetics analysis (based on $\mathrm{F}_{\mathrm{ST}}$ measure of genetic differentiation), listing the hypotheses tested, the variables included in each model, model support based on AICc and BIC 
and evidence weights of each model (AICcmin and BICew) and the $95 \%$ confidence intervals of variables in the two best supported models.

\begin{tabular}{lllllll}
\hline Hypothesis & Variables & AICc & BIC & AICcmin & BICew & 95\% CI \\
\hline Topography & Altitude & $\mathbf{- 8 5 . 8 8 4}$ & $\mathbf{- 9 2 . 6 7 3}$ & $\mathbf{0 . 4 7 7}$ & $\mathbf{0 . 3 5 1}$ & $\mathbf{0 . 0 0 5 - 0 . 0 1 1}$ \\
Land cover & Land cover 4 & -79.852 & -86.642 & 0.023 & 0.017 & \\
Anthropogenic & Human footprint & $\mathbf{- 7 7 . 8 2 0}$ & $\mathbf{- 8 4 . 6 1 0}$ & 0.008 & 0.006 & \\
Ecoregions & Ecoregions 4 & $\mathbf{- 8 5 . 5 8 9}$ & $\mathbf{- 9 2 . 3 7 9}$ & $\mathbf{0 . 4 1 2}$ & $\mathbf{0 . 3 0 3}$ & $\mathbf{0 . 0 0 3 - 0 . 0 0 6}$ \\
Forest & Percent tree cover & $\mathbf{- 7 9 . 4 0 1}$ & -86.191 & 0.019 & 0.014 & \\
Hydrology & Streams 2a & -81.253 & -88.042 & 0.047 & 0.035 & \\
Hydro-Land & Land cover + Streams & -74.705 & -88.193 & 0.002 & 0.037 & \\
Anthro-Eco & Human + Ecoregions & -76.591 & -90.078 & 0.005 & 0.096 & \\
Anthro-Topo & Human + Altitude & -77.343 & -90.831 & 0.007 & 0.140 & \\
\hline
\end{tabular}

Table 4 - Parameter estimation based on the best-supported model (scenario 4) in the approximate Bayesian computation model-based inference of the demographic history of Plecotus balensis and results of the bias and precession on parameter estimation analysis (MR bias = mean relative bias; RMedAD = relative median absolute deviation). Smaller accuracy values correspond to more precise parameter estimation. See Supplementary Fig. S1 for scenario details.

\begin{tabular}{llllll}
\hline Parameter & Median & Q5\% & Q95\% & MR bias & RMedAD \\
\hline Na: current South population size & $9.70 \mathrm{E}+03$ & $8.52 \mathrm{E}+03$ & $9.97 \mathrm{E}+03$ & 0.18 & 0.31 \\
N2: current North population size & $9.20 \mathrm{E}+04$ & $2.09 \mathrm{E}+04$ & $5.71 \mathrm{E}+05$ & 0.26 & 0.36 \\
T4: time of South population decline & $7.66 \mathrm{E}+01$ & $1.48 \mathrm{E}+01$ & $5.57 \mathrm{E}+02$ & 0.29 & 0.42 \\
N1a: past South population size after split & $5.99 \mathrm{E}+04$ & $2.38 \mathrm{E}+04$ & $1.39 \mathrm{E}+05$ & 0.20 & 0.33 \\
T3: time of population split & $4.48 \mathrm{E}+04$ & $1.75 \mathrm{E}+04$ & $7.77 \mathrm{E}+04$ & 0.44 & 0.43 \\
\hline
\end{tabular}

\section{Figure Legends}

Figure 1 - Map of the five sampled mountain ranges in Ethiopia presented over a digital elevation model with the location of the Rift Valley marked with red stripes. The insert shows the location of Ethiopia in eastern Africa.

Figure 2 - Projected probability of occurrence forPlecotus balensis across the horn of Africa based on ecological niche modelling outputs for a) present; b) past (Last Glacial Maximum, $\sim 21 \mathrm{~K}$ ya); c) future (2070) severe emissions scenario (RCP 8.5); and d) future (2070) moderate emissions scenario (RCP 4.5) climatic conditions. Probability of occurrence ranges from high in orange to low in blue; stars denote the location of mountain ranges sampled in this study.

Figure 3 - Plecotus balensis genetic population structure: a) colour-coded mountain ranges sampled in the study; b) Bayesian phylogenetic tree based on the combined cytb and HVI mtDNA regions, with Plecotus austriacus as an outgroup and showing branch support $>0.8$; c) results of the STRUCTURE analysis dividing the microsatellite dataset into two population clusters, south (yellow) and north (green) of the Rift Valley; and d) haplotype network based on the combined cytb and HVI mtDNA regions, indicating number of mutation steps.

Figure 4 - Projected movement density based on the effect of altitude (a) and ecoregions (b) on genetic connectivity betweenPlecotus balensis population. 


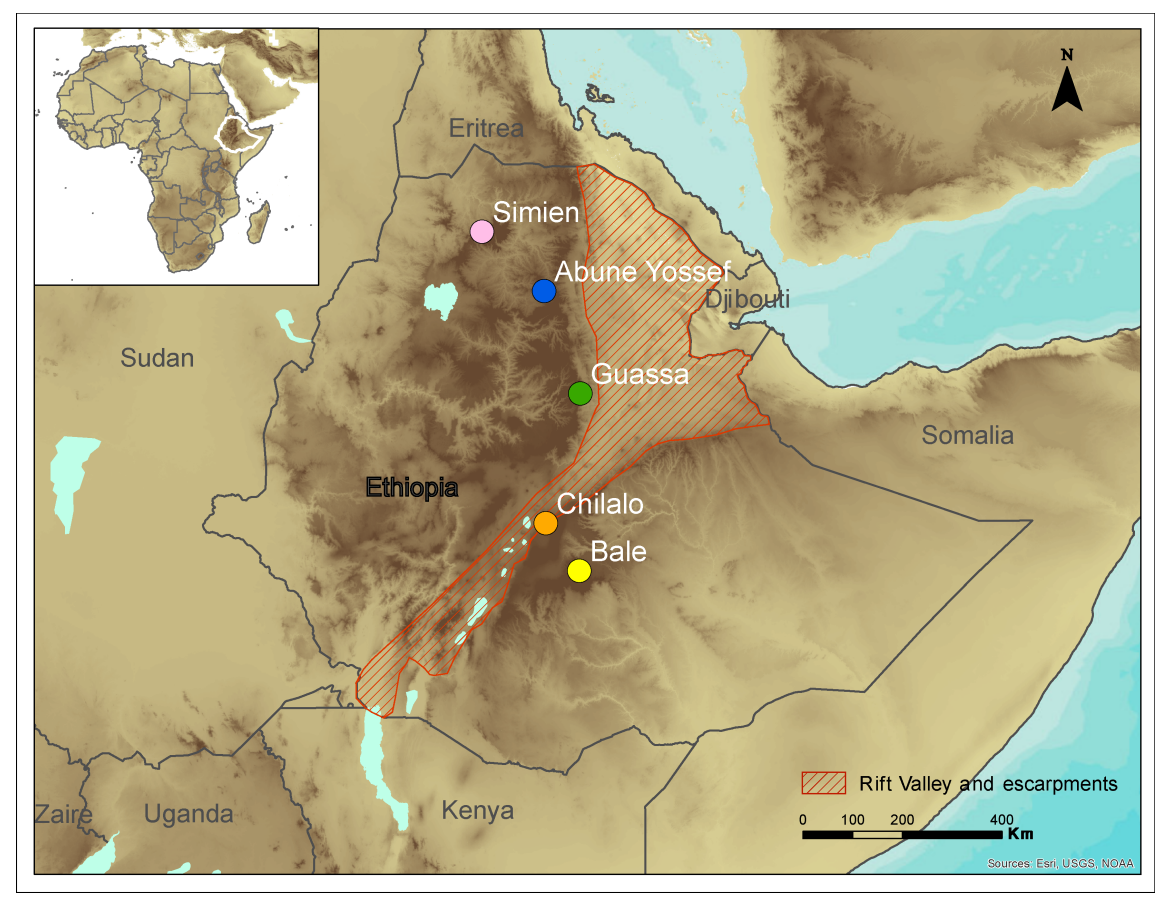



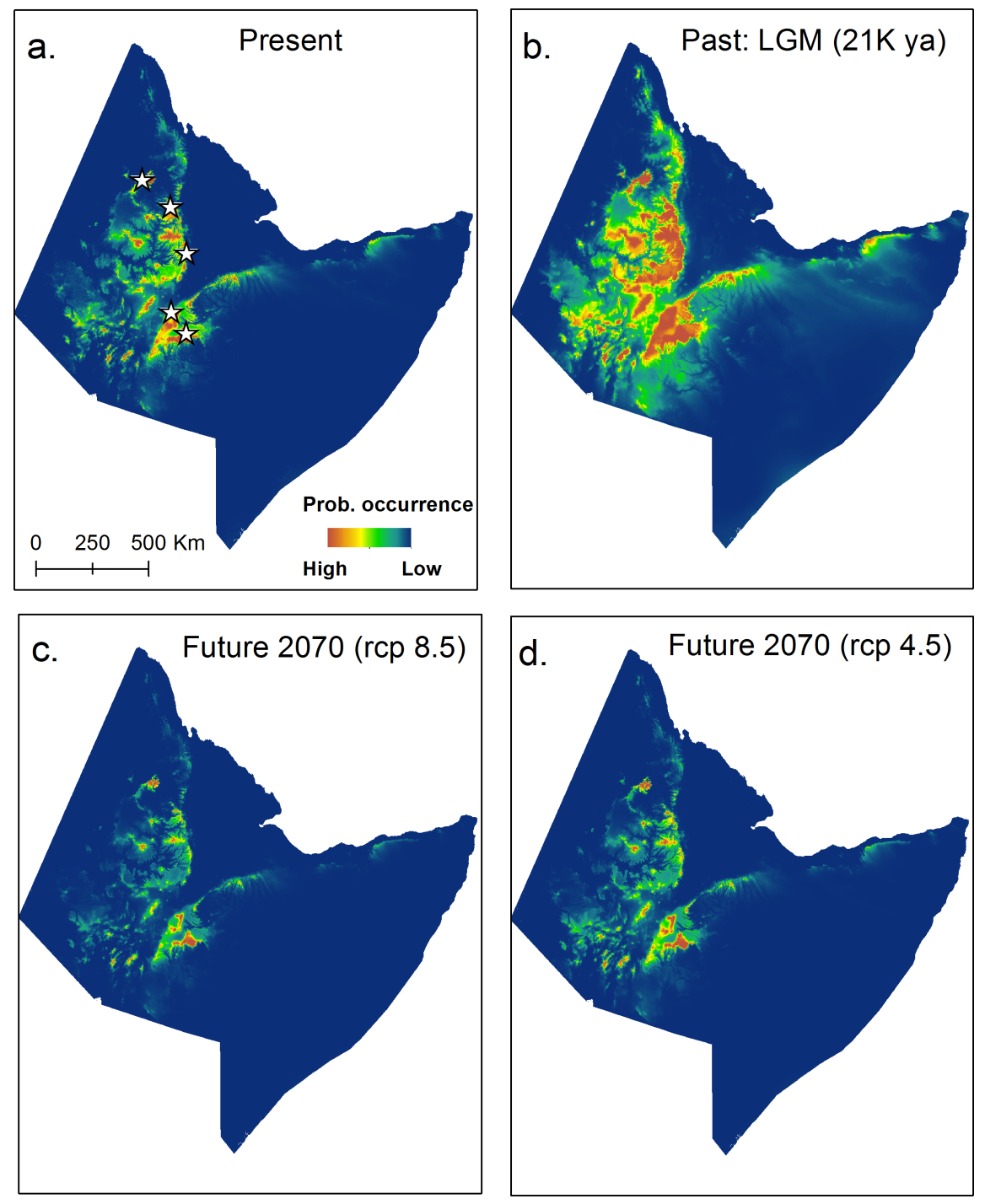


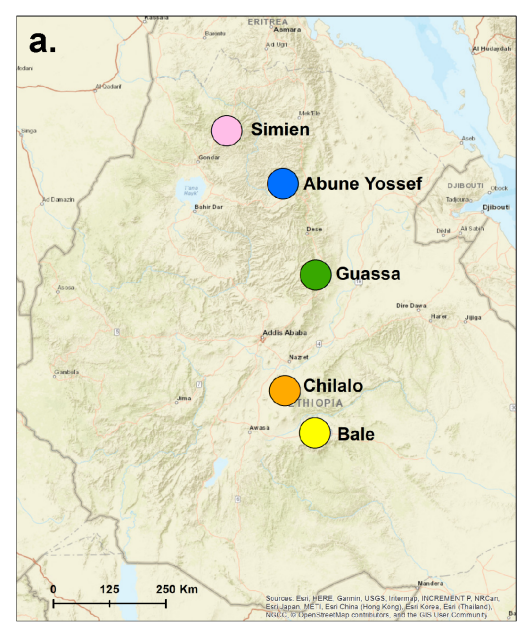

b.

c.

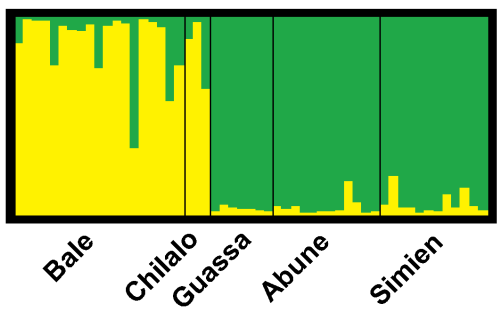

b. $\quad 0.8\left[\begin{array}{lll}\text { Bal0OHH } \\ \text { Baleoss }\end{array}\right.$

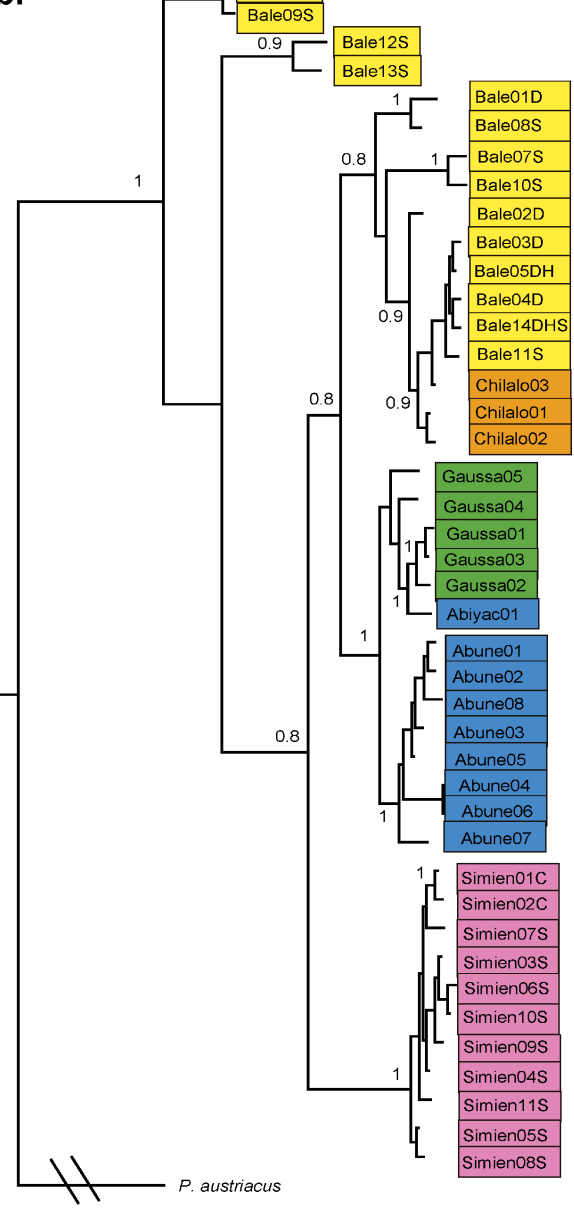

d.

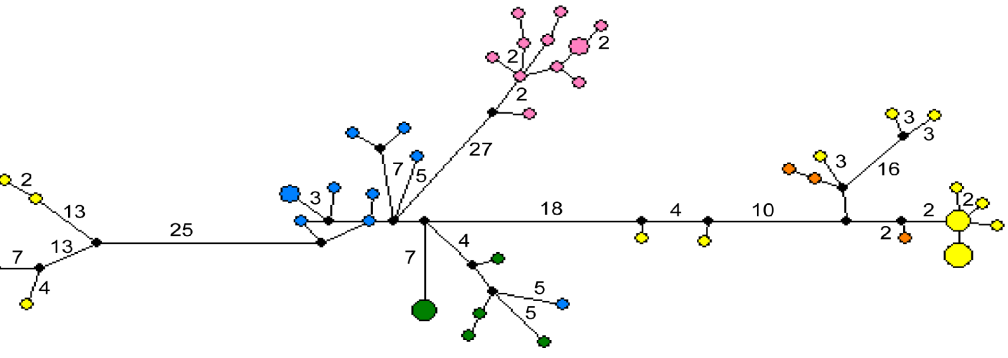



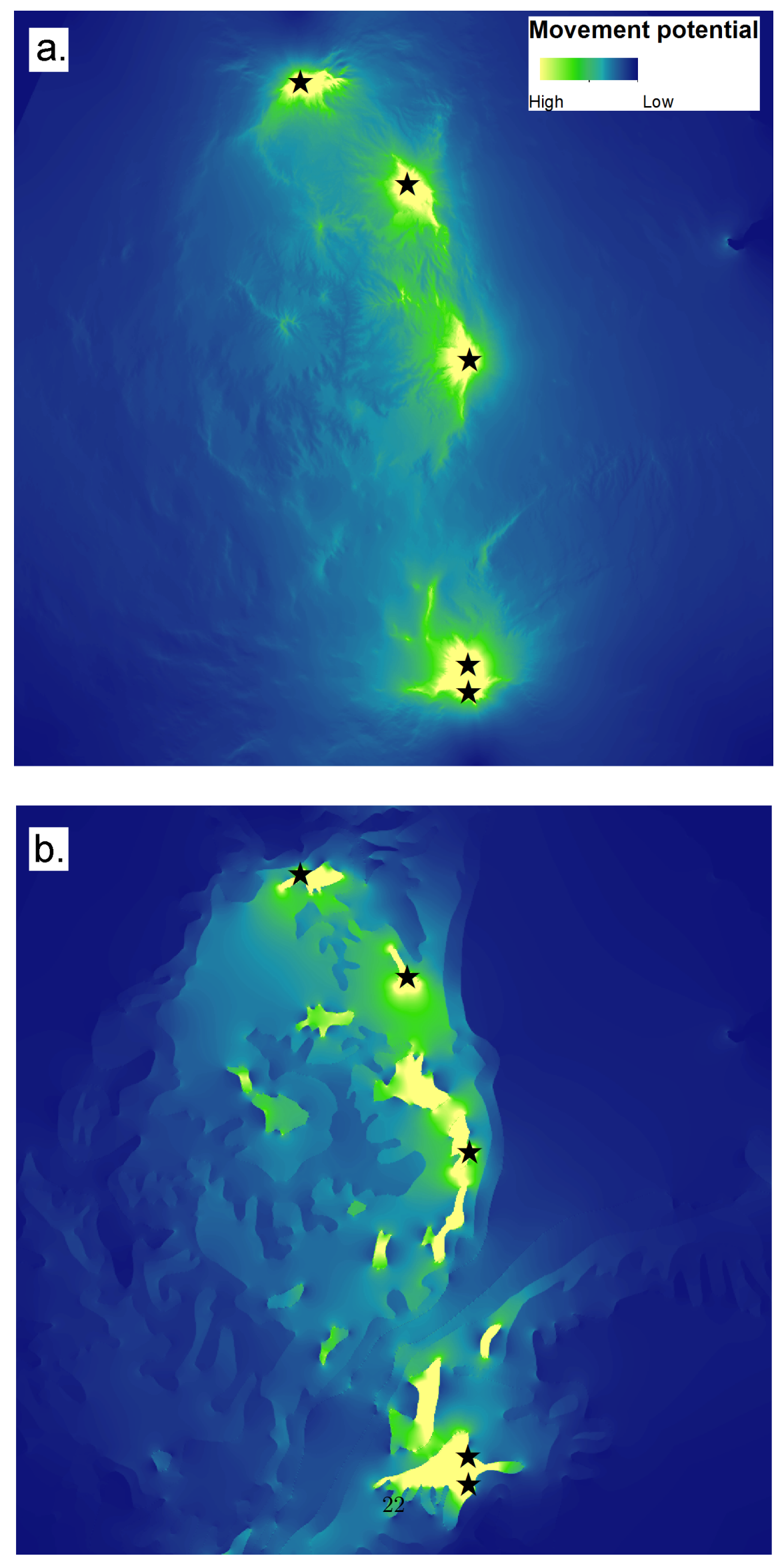